Research

Open Access

\title{
Ventilator-induced endothelial activation and inflammation in the lung and distal organs
}

\author{
Maria A Hegeman ${ }^{1,2}$, Marije P Hennus², Cobi J Heijnen ${ }^{1}$, Patricia AC Specht ${ }^{3}$, \\ Burkhard Lachmann ${ }^{3,4}$, Nicolaas JG Jansen², Adrianus J van Vught ${ }^{2}$ and Pieter M Cobelens ${ }^{1,5}$
}

\begin{abstract}
${ }^{1}$ Laboratory of Psychoneuroimmunology, University Medical Center Utrecht, Lundlaan 6, Utrecht, 3584 EA, the Netherlands 2Department of Pediatric Intensive Care, University Medical Center Utrecht, Lundlaan 6, Utrecht, 3584 EA, the Netherlands ${ }^{3}$ Department of Anesthesiology, Erasmus Medical Center, Dr. Molewaterplein 50-60, Rotterdam, 3015 GE, the Netherlands ${ }^{4}$ Department of Anesthesiology and Intensive Care Medicine, Charité Campus Virchow-Klinikum, Humboldt-University, Augustenburger Platz 1, Berlin, D-13353, Germany (current address)

5Department of Intensive Care Medicine, University Medical Center Utrecht, Heidelberglaan 100, Utrecht, 3584 CX, the Netherlands
\end{abstract}

Corresponding author: Cobi J Heijnen, c.heijnen@umcutrecht.nl

Received: 11 Sep 2009 Revisions requested: 19 Oct 2009 Revisions received: 23 Oct 2009 Accepted: 16 Nov 2009 Published: 16 Nov 2009

Critical Care 2009, 13:R182 (doi:10.1186/cc8168)

This article is online at: http://ccforum.com/content/13/6/R182

(c) 2009 Hegeman et al.; licensee BioMed Central Ltd.

This is an open access article distributed under the terms of the Creative Commons Attribution License (http://creativecommons.org/licenses/by/2.0), which permits unrestricted use, distribution, and reproduction in any medium, provided the original work is properly cited.

\begin{abstract}
Introduction Results from clinical studies have provided evidence for the importance of leukocyte-endothelial interactions in the pathogenesis of pulmonary diseases such as acute lung injury (ALI) and acute respiratory distress syndrome (ARDS), as well as in systemic events like sepsis and multiple organ failure (MOF). The present study was designed to investigate whether alveolar stretch due to mechanical ventilation (MV) may evoke endothelial activation and inflammation in healthy mice, not only in the lung but also in organs distal to the lung.
\end{abstract}

Methods Healthy male $\mathrm{C} 3 \mathrm{H} / \mathrm{HeN}$ mice were anesthetized, tracheotomized and mechanically ventilated for either 1,2 or 4 hours. To study the effects of alveolar stretch in vivo, we applied a MV strategy that causes overstretch of pulmonary tissue i.e. $20 \mathrm{cmH}_{2} \mathrm{O}$ peak inspiratory pressure (PIP) and $0 \mathrm{cmH}_{2} \mathrm{O}$ positive end expiratory pressure (PEEP). Non-ventilated, shamoperated animals served as a reference group (non-ventilated controls, NVC).

Results Alveolar stretch imposed by MV did not only induce de novo synthesis of adhesion molecules in the lung but also in organs distal to the lung, like liver and kidney. No activation was observed in the brain. In addition, we demonstrated elevated cytokine and chemokine expression in pulmonary, hepatic and renal tissue after $\mathrm{MV}$ which was accompanied by enhanced recruitment of granulocytes to these organs.

Conclusions Our data implicate that MV causes endothelial activation and inflammation in mice without pre-existing pulmonary injury, both in the lung and distal organs.

\section{Introduction}

Critically ill patients in the intensive care unit often require mechanical ventilation (MV) to adequately oxygenate vital organs. Although artificial ventilation is lifesaving, the procedure itself may lead to serious damage in both healthy and diseased lungs [1]. Studies have revealed that the cyclic opening and collapse of alveoli during MV may provoke alveolar stretch and subsequently result in ventilator-induced lung injury (VILI) $[2,3]$. Important features of VILI are increased cytokine or chemokine production, alveolar-capillary permeability, proteinrich edema formation and, ultimately, impaired gas exchange [4-6].

ALI: acute lung injury; ARDS: acute respiratory distress syndrome; BE: base excess; BSA: bovine serum albumin; ELISA: enzyme-linked immunosorbent assay; $\mathrm{FiO}_{2}$ : fractional inspired oxygen concentration; H\&E: hematoxylin and eosin; ICAM: intercellular adhesion molecule; Ig: Immunoglobulin; IL: interleukin; KC: keratinocyte-derived chemokine; MOF: multiple-organ failure; MPO: myeloperoxidase; MV: mechanical ventilation; NVC: non-ventilated controls; $\mathrm{PaCO}_{2}$ : partial pressure of arterial carbon dioxide; $\mathrm{PaO}_{2}$ : partial pressure of arterial oxygen; PBS: phosphate-buffered saline; PECAM: platelet-endothelial cell adhesion molecule; PEEP: positive end expiratory pressure; PIP: peak inspiratory pressure; RT-PCR: reverse transcriptase polymerase chain reaction; TNF: tumor necrosis factor; VCAM: vascular cell adhesion molecule; VILI: ventilator-induced lung injury. 
Pro-inflammatory cytokines such as IL-1 $\beta$ and TNF- $\alpha$ are secreted by alveolar macrophages upon mechanical stretch [7] and are capable of stimulating endothelial activation [8]. In turn, cytokine-activated endothelial cells secrete chemokines and express adhesion molecules on their surface resulting in enhanced leukocyte adhesiveness and transmigration of activated immune cells across the endothelium of inflamed tissue [8-10]. Vascular adhesion molecules that belong to the selectin family (P-selectin and E-selectin) mediate leukocyte margination and rolling along the blood vessel wall, whereas members of the immunoglobulin (Ig) superfamily (vascular cell adhesion molecule (VCAM)-1, intercellular adhesion molecule (ICAM)-1 and platelet-endothelial cell adhesion molecule (PECAM)-1) participate in leukocyte adhesion and transmigration into underlying tissue [11]. Previously, it has been shown that soluble adhesion molecule levels are elevated in patients with serious lung diseases such as acute lung injury (ALI) and acute respiratory distress syndrome (ARDS) [12,13]. Moreover, augmented P-selectin, VCAM-1 and ICAM-1 expression was found in pulmonary tissue after MV [14] suggesting that adhesion molecules may play a crucial role in the pathogenesis of VILI.

Most critically ill patients do not succumb to lung deterioration associated with MV but to multiple-organ failure (MOF) caused by a systemic inflammatory response syndrome $[15,16]$. As a mechanism of MOF, it has been hypothesized that ventilator-induced lung inflammation may elicit release of inflammatory mediators into the circulation, thereby amplifying a pro-inflammatory systemic environment and eventually leading to detrimental effects in distal organs [17-19]. As high levels of inflammatory mediators in the periphery are believed to be important in the pathogenesis of $\operatorname{MOF}[20,21]$, systemic effects of MV have been proposed to be responsible $[18,19]$. Similar to sepsis-induced MOF $[22,23]$ activation of endothelial cells in distal organs might be essential in the development of ventilator-induced MOF.

We designed this study to investigate whether ventilatorinduced alveolar stretch may cause endothelial activation in healthy mice, not only in the lung but also in organs distal to the lung. To determine endothelial activation in these organs we assessed de novo synthesis of adhesion molecules. Moreover, we examined ventilator-induced effects on the inflammatory state of pulmonary, hepatic, renal and cerebral tissue.

\section{Materials and methods Animals}

The experiments were performed in accordance with international guidelines and approved by the experimental animal committee of the Erasmus Medical Center Rotterdam. A total of 42 adult male $\mathrm{C} 3 \mathrm{H} / \mathrm{HeN}$ mice (Harlan $\mathrm{CPB}$, Zeist, the Netherlands), weighing 25 to $30 \mathrm{~g}$, were randomly assigned to different experimental groups.
To investigate the effects of alveolar stretch in vivo, we applied a MV strategy that has been described to cause overstretch of pulmonary tissue $[24,25]$. The method of MV was based on the first experiments performed in mice [26]. Thirty mice were tracheotomized under inhalation anesthesia $(65 \%$ nitrous oxide, 33\% oxygen, 2\% isoflurane; Pharmachemie, Haarlem, the Netherlands). Subsequently, anesthesia was continued with $24 \mathrm{mg} / \mathrm{kg} / \mathrm{h}$ intraperitoneal sodium pentobarbital (Algin, Maassluis, the Netherlands). Additional anesthesia was given when necessary. The intraperitoneal administered anesthesia fluid was sufficient to correct for hypovolemia. Muscle relaxation was attained with $0.4 \mathrm{mg} / \mathrm{kg} / \mathrm{h}$ intramuscular pancuronium bromide (Organon Technika, Boxtel, the Netherlands). The animals were connected to a Servo Ventilator 300 (SiemensElema, Solna, Sweden) and ventilated for one, two or four hours in a pressure-controlled time-cycled mode ( $n=9$ to 10 per group), at a fractional inspired oxygen concentration $\left(\mathrm{FiO}_{2}\right)$ of 1.0, inspiration to expiration ratio of $1: 2$ and frequency of 20 to 30 breaths/min to maintain normocapnia. Peak inspiratory pressure (PIP) was set at $20 \mathrm{cmH}_{2} \mathrm{O}$ and positive end-expiratory pressure (PEEP) at $0 \mathrm{cmH}_{2} \mathrm{O}$. A polyethylene catheter was inserted into the carotid artery and blood gas determinations were performed using a $\mathrm{pH} / \mathrm{blood}$ gas analyzer $(\mathrm{ABL}$ 505; Radiometer, Copenhagen, Denmark). Body temperature was maintained between 36 and $38^{\circ} \mathrm{C}$ with a heating device (UNO Roestvaststaal, Zevenaar, the Netherlands). Eight healthy non-ventilated, sham-operated mice served as a reference group (non-ventilated controls (NVC)). To investigate whether the high partial pressure of arterial oxygen $\left(\mathrm{PaO}_{2}\right)$ levels associated with our MV strategy may contribute to changes in the immune response, spontaneously breathing animals $(n=6)$ were placed in an oxygen saturated box for four hours $\left(\mathrm{FiO}_{2}\right.$ of 1.0 , hyperoxia). This exposure time was chosen, because it resembles the longest period of time that mice were subjected to MV. All animals were sacrificed with an overdose of intraperitoneal sodium pentobarbital (Organon, Oss, the Netherlands).

\section{Histology}

Two mice per group were perfused with PBS. Pulmonary tissue was directly removed, frozen in liquid nitrogen and stored at $-80^{\circ} \mathrm{C}$ to evaluate lung architecture and presence of granulocytes. Before being snap frozen, lungs were filled with Tissue-Tek (Sakura Finetek, Zoeterwoude, the Netherlands).

Cryosections $(5 \mu \mathrm{m})$ were cut on a cryostat microtome (Leica Microsystems, Nussloch, Germany) and fixed with acetone for 10 minutes. To assess pulmonary histopathology, longitudinal sections were stained with H\&E (Klinipath, Duiven, the Netherlands).

\section{Tissue homogenates}

Pulmonary, hepatic, renal and cerebral tissue (from four to eight mice per group) was directly removed and frozen in liquid nitrogen to evaluate endothelial activation and inflammation. 
Tissues were pulverized using a liquid nitrogen-cooled mortar and pestle, divided in several fractions and stored at $-80^{\circ} \mathrm{C}$ allowing us to use the lung, liver, kidney and brain from one animal for multiple analyses. All analyses were performed in a blinded-setup.

\section{Myeloperoxidase assay}

For lung and brain, myeloperoxidase (MPO) activity was determined as described previously [27]. In short, pulverized tissues were homogenized in $50 \mathrm{mM}$ HEPES buffer $(\mathrm{pH}$ 8.0), centrifuged and pellets were homogenized again in water and 0.5\% cetyltrimethylammonium chloride (Merck, Darmstadt, Germany). After centrifugation, supernatants were diluted in $10 \mathrm{mM}$ citrate buffer ( $\mathrm{pH} 5.0$ ) and $0.22 \%$ cetyltrimethylammonium chloride. A substrate solution containing $3 \mathrm{mM} \mathrm{3',5,5'-}$ tetramethylbenzidine dihydrochloride (Sigma-Aldrich, Steinheim, Germany), $120 \mu \mathrm{M}$ resorcinol (Merck, Darmstadt, Germany) and $2.2 \mathrm{mM}$ hydrogen peroxide $\left(\mathrm{H}_{2} \mathrm{O}_{2}\right)$ in distilled water was added. Reaction mixtures were incubated for 20 minutes at room temperature and stopped by addition of $4 \mathrm{M}$ sulfuric acid $\left(\mathrm{H}_{2} \mathrm{SO}_{4}\right)$ followed by determination of optical density at $450 \mathrm{~nm}$. MPO activity of a known amount of MPO units (Sigma-Aldrich, Steinheim, Germany) was used as reference. For liver and kidney, pulverized tissues were homogenized in lysis buffer with protease inhibitors. In supernatants MPO activity was analyzed by ELISA according to the manufacturer's instructions (Hycult Biotechnology, Uden, the Netherlands). To correct for homogenization procedures, total protein concentration of samples was determined with a BCA protein-assay (Pierce Biotechnology, Rockford, IL, USA) using BSA as standard.

\section{Quantitative real-time RT-PCR analysis}

Total RNA was isolated from pulverized tissues with TRIzol ${ }^{\circledR}$ reagent (Invitrogen, Paisley, UK). cDNA was synthesized from total RNA with SuperScript Reverse Transcriptase kit (Invitro- gen, Paisley, UK). Quantitative real-time RT-PCR reaction was performed with iQ5 Real-Time PCR Detection System (Biorad, Hercules, CA, USA) using primers for E-selectin, VCAM1, ICAM-1, PECAM-1, IL-1 $\beta$, TNF- $\alpha$ and keratinocyte-derived chemokine (KC; murine homologue of IL-8; Table 1). To confirm appropriate amplification, size of PCR products was verified by agarose gel separation. Data were normalized for expression of internal controls $\beta$-actin and glyceraldehyde 3phosphate dehydrogenase.

\section{Statistical analysis}

Data are expressed as mean \pm standard error of the mean. All parameters were analyzed by one-way analysis of variance (ANOVA) with Least Significant Difference (LSD) post-test. $P$ values less than 0.05 were considered statistically significant.

\section{Results}

\section{Stability of the model}

MV was applied to healthy mice to induce alveolar stretch. All mice survived the ventilatory protocol and produced urine throughout the experiment. Arterial blood gas analysis of ventilated mice showed a stable oxygen tension $\left(\mathrm{PaO}_{2}\right)$ with carbon dioxide tension $\left(\mathrm{PaCO}_{2}\right), \mathrm{pH}$ and base excess (BE) within the physiological range (Table 2 ). In addition, pulmonary architecture was preserved during the experiment (Figure 1).

\section{Effects of MV on inflammatory state of pulmonary tissue} Endothelial activation

We studied the effect of MV on endothelial activation in pulmonary tissue by measuring de novo synthesis of adhesion molecules. Compared with NVC, enhanced mRNA expression of E-selectin and VCAM-1 was noticed after two and four hours of MV (Figures $2 a$ and $2 b$ ). No ventilator-induced changes in ICAM-1 and PECAM-1 mRNA were found in the lung (Figures $2 \mathrm{c}$ and $2 \mathrm{~d}$ ).

Table 1

Primers used for quantitative real-time RT-PCR

\begin{tabular}{lll}
\hline & Forward & Reverse \\
\hline E-selectin & CAACgTCTAggTTCAAAACAATCAg & TTAAgCAggCAAgAggAACCA \\
VCAM-1 & TgAAgTTggCTCACAATTAAgAATT & TgCgCAgTAgAgTgCAAggA \\
ICAM-1 & ggAgACgCAgAggACCTTAACAg & CgACgCCgCTCAgAAgACC \\
PECAM-1 & ACgATgCgATggTgTATAAC & ACCTTgggCTTggATACg \\
IL-1 $\beta$ & CAACCAACAAgTgATATTCTCCATg & gATCCACACTCTCCAgCTgCA \\
TNF- $\alpha$ & gCggTgCCTATgTCTCAg & gCCATTTgggACTTCTCATC \\
KC & AAAAggTgTCCCCAAgTAACg & gTCAgAAgCCAgCgTTCAC \\
$\beta$-actin & AgAgggAAATCgTgCgTgAC & CAATAgTgATgACCTggCCgT \\
GAPDH & TgAAgCAggCATCTgAggg & CgAAggTggAAgAgTgggAg
\end{tabular}

GAPDH = glyceraldehyde 3-phosphate dehydrogenase; ICAM = intercellular adhesion molecule; IL = interleukin; KC = keratinocyte-derived chemokine; PECAM = platelet-endothelial cell adhesion molecule; TNF = tumor necrosis factor; VCAM = vascular cell adhesion molecule. 
Table 2

\section{Oxygenation variables after one, two and four hours of mechanical ventilation}

\begin{tabular}{lllll}
\hline Time (hours) & $\mathrm{PaO}_{2}(\mathrm{mmHg})$ & $\mathrm{PaCO}_{2}(\mathrm{mmHg})$ & $\mathrm{pH}$ & $\mathrm{BE}$ \\
\hline 1 & $568.6 \pm 23.1$ & $31.0 \pm 2.8$ & $7.46 \pm 0.02$ & $-0.8 \pm 1.4$ \\
2 & $509.7 \pm 22.0$ & $35.4 \pm 2.3$ & $7.42 \pm 0.02$ & $-1.5 \pm 0.6$ \\
4 & $493.4 \pm 24.9$ & $45.4 \pm 4.3$ & $7.32 \pm 0.03$ & $-4.0 \pm 0.9$ \\
\hline
\end{tabular}

Data are presented as mean \pm standard error of the mean. $\mathrm{BE}=$ base excess; $\mathrm{PaCO}_{2}=$ partial pressure of arterial carbon dioxide; $\mathrm{PaO}=$ partial pressure of arterial oxygen.

Cytokine and chemokine expression

After two and four hours of MV, significantly higher mRNA expression of the pro-inflammatory cytokines IL-1 $\beta$ and TNF- $\alpha$ were observed (Figures $2 \mathrm{e}$ and $2 \mathrm{f}$ ). In addition, $\mathrm{MV}$ induced an increase in mRNA expression of the chemokine KC (Figure $2 \mathrm{~g}$ ).

\section{Granulocyte recruitment}

To investigate whether the ventilator-induced endothelial activation and chemokine expression was accompanied by recruitment of granulocytes to inflamed pulmonary tissue, MPO activity was determined in total lung homogenates (Figure $2 \mathrm{~h}$ ). Elevated MPO activity was found after one, two and four hours of MV, which correlated with the presence of granulocytes observed in frozen pulmonary sections stained for H\&E (Figure 1). Furthermore, histology of ventilated lungs showed margination of granulocytes to the blood vessel wall.
Exudation of granulocytes into the alveolar space was not observed.

\section{Contribution of hyperoxia}

To examine whether the high $\mathrm{PaO}_{2}$ levels associated with our MV strategy contributed to changes in the pulmonary immune response, we exposed spontaneously breathing mice to $100 \%$ oxygen levels for four hours $\left(\mathrm{FiO}_{2}\right.$ of 1.0 , hyperoxia). As depicted in Figures 1 and 2, hyperoxia-exposed mice $\left(\mathrm{O}_{2}\right.$ group) showed a similar adhesion molecule, cytokine and chemokine expression, MPO activity and lung histopathology compared with NVC.

\section{Figure 1}

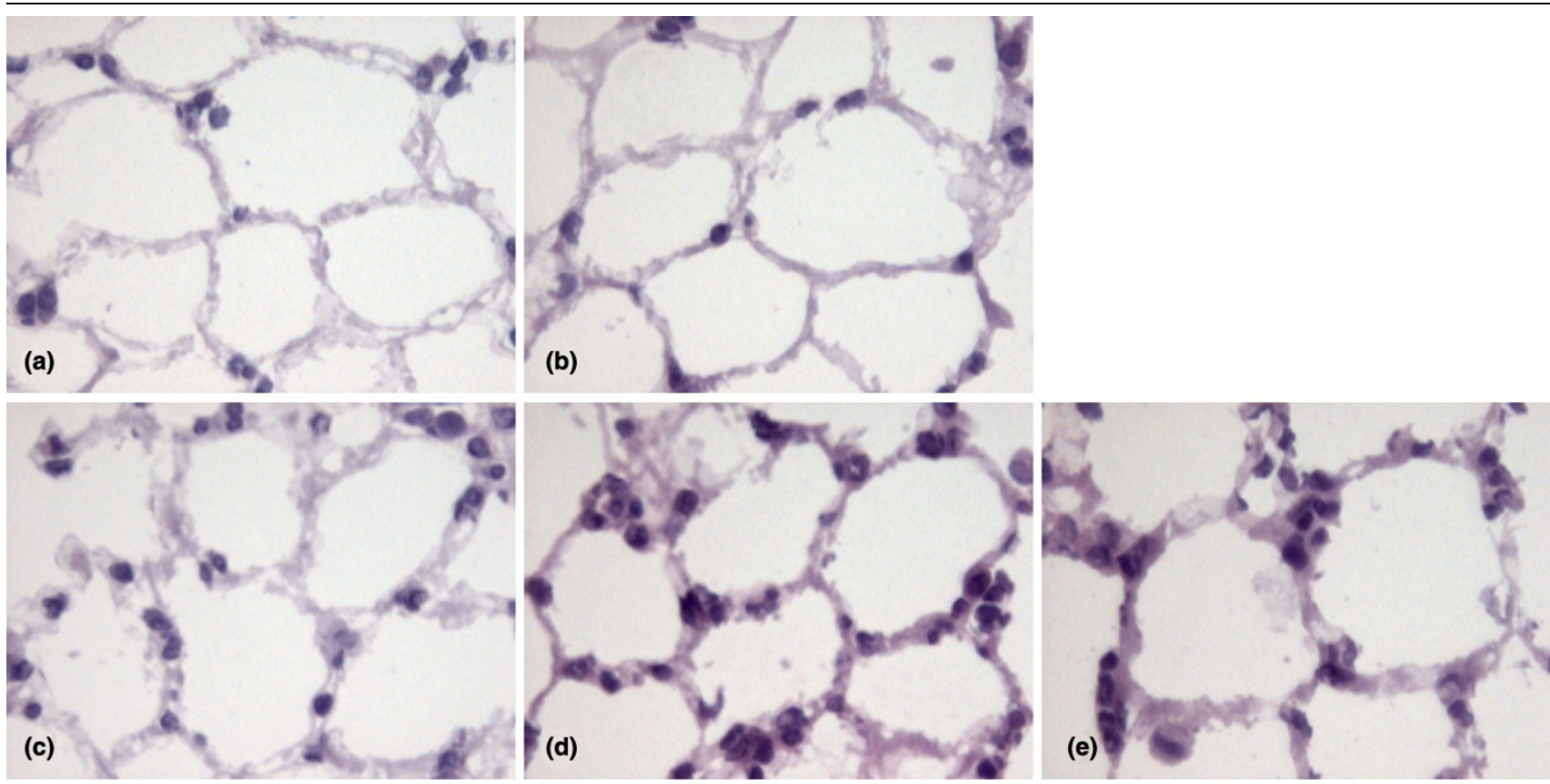

Histopathology of pulmonary tissue. Frozen lung sections were stained with $\mathrm{H} \& \mathrm{E}$ to analyze lung architecture and presence of granulocytes in pulmonary tissue. (a) Non-ventilated controls, (b) mice exposed to hyperoxia for four hours, and mice mechanically ventilated for (c) one, (d) two and (e) four hours. Magnification $\times 500$. 
Figure 2
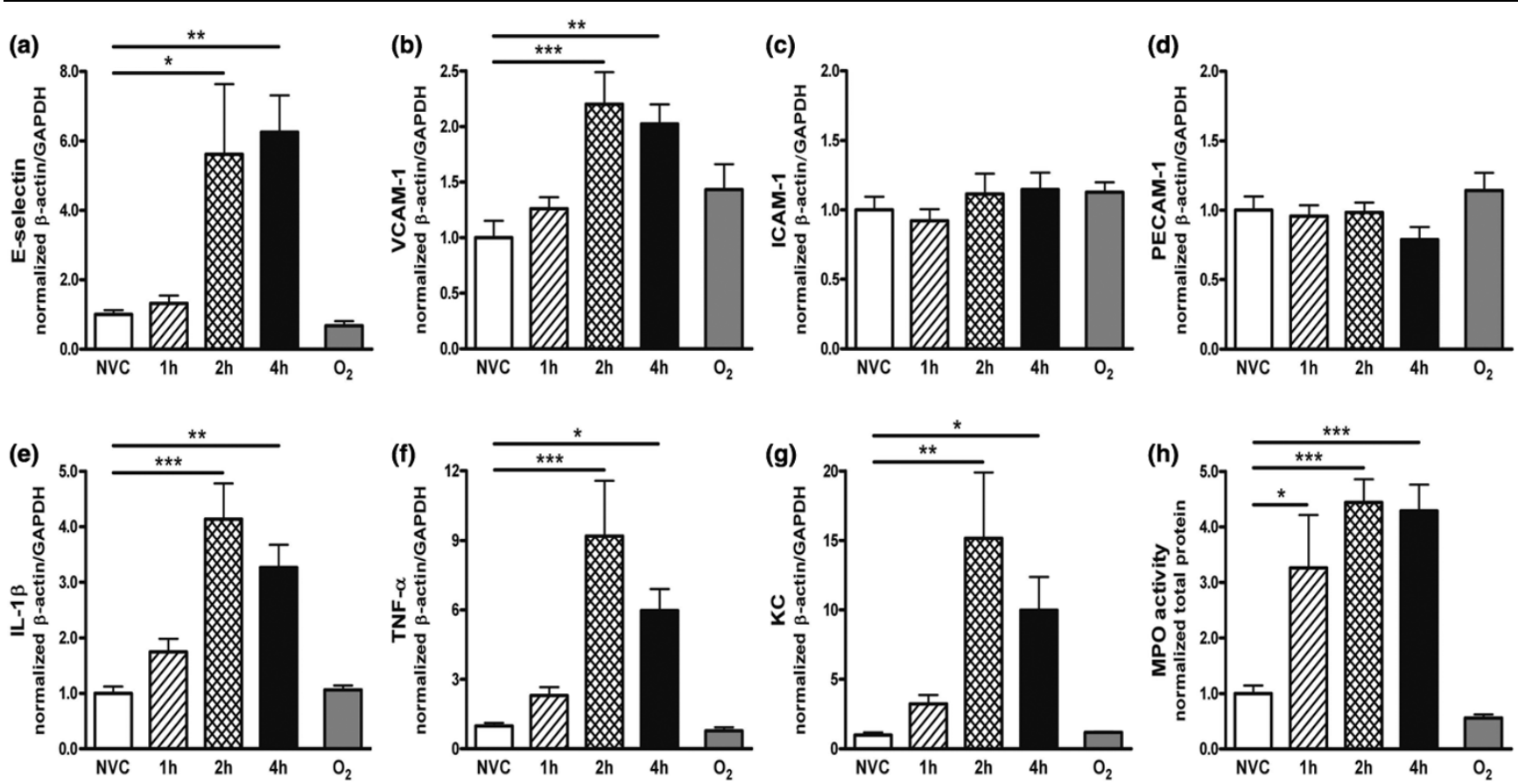

Ventilator-induced endothelial activation and inflammation in pulmonary tissue. In total lung homogenates, mRNA expression of the adhesion molecules (a) E-selectin, (b) vascular cell adhesion molecule (VCAM)-1, (c) intercellular adhesion molecule (ICAM)-1 and (d) platelet-endothelial cell adhesion molecule (PECAM)-1 was determined by quantitative real time RT-PCR. In addition, we studied ventilator-induced pulmonary inflammation by measuring mRNA expression of the pro-inflammatory cytokines (e) IL-1 $\beta$ and (f) TNF- $\alpha$ and the chemokine (g) keratinocyte-derived chemokine (KC). In total lung homogenates, (h) myeloperoxidase (MPO) activity was determined as a measure of granulocyte infiltration. Data are expressed as mean \pm standard error of the mean of four to eight mice for each group $\left({ }^{\star} P<0.05,{ }^{\star \star} P<0.01,{ }^{\star \star \star} P<0.001\right.$ vs. non-ventilated controls (NVC)). 1 $\mathrm{h}=$ mechanically ventilated for one hour; $2 \mathrm{~h}=$ mechanically ventilated for two hours; $4 \mathrm{~h}=$ mechanically ventilated for four hours; $\mathrm{O}_{2}=$ hyperoxia for four hours; GAPDH = glyceraldehyde 3-phosphate dehydrogenase.

\section{Effects of MV on inflammatory state of hepatic, renal and cerebral tissue \\ Endothelial activation}

The effect of MV on endothelial activation in hepatic, renal and cerebral tissue was investigated by analyzing de novo synthesis of adhesion molecules. In the liver, higher mRNA expression of E-selectin and ICAM-1 was observed after four hours of MV in comparison with NVC (Figures 3a and 3c). VCAM-1 mRNA was already elevated in hepatic tissue after two hours of $\mathrm{MV}$ and further increased after four hours (Figure $3 \mathrm{~b}$ ). No differences were found in PECAM-1 mRNA (Figure 3d). Also in the kidney, we noticed increased mRNA expression of Eselectin, VCAM-1 and ICAM-1 after two and four hours of MV (Figures 4a to 4c). Minimal changes in PECAM-1 mRNA were found in renal tissue of ventilated mice (Figure 4d). In the brain, MV did not induce a significant change in adhesion molecule mRNA expression as compared with NVC (data not shown).

\section{Cytokine and chemokine expression}

In the liver, IL-1 $\beta$ and TNF- $\alpha$ mRNA expression was enhanced after four hours of MV (Figures $3 e$ and $3 f$ ) although the difference in TNF- $\alpha$ mRNA between four hours of MV and NVC did not reach statistical significance $(P=0.09)$. KC mRNA was significantly elevated in hepatic tissue after two hours of MV and further increased after four hours (Figure $3 \mathrm{~g}$ ). In the kidney of ventilated mice, we noticed higher IL-1 $\beta$ mRNA expression at four hours whereas no changes were found in TNF- $\alpha$ mRNA expression (Figures $4 \mathrm{e}$ and $4 \mathrm{f}$ ). Increased $\mathrm{KC}$ mRNA was already present after one and two hours of MV (Figure $4 \mathrm{~g}$ ). In the brain, MV did not induce a detectable cytokine or chemokine response (data not shown).

\section{Granulocyte recruitment}

To determine if enhanced endothelial activation and chemokine expression was accompanied by recruitment of granulocytes to inflamed distal organs, we analyzed MPO activity in hepatic, renal and cerebral tissue. In the liver of ventilated mice, enhanced MPO activity was observed already at one hour and was most pronounced at four hours (Figure $3 \mathrm{~h}$ ). Also in renal tissue, MPO activity was higher after 1 hour of MV and increased further at two and four hours (Figure 4h). In the brain, MPO activity was below detection level in all experimental groups (data not shown). 
Figure 3
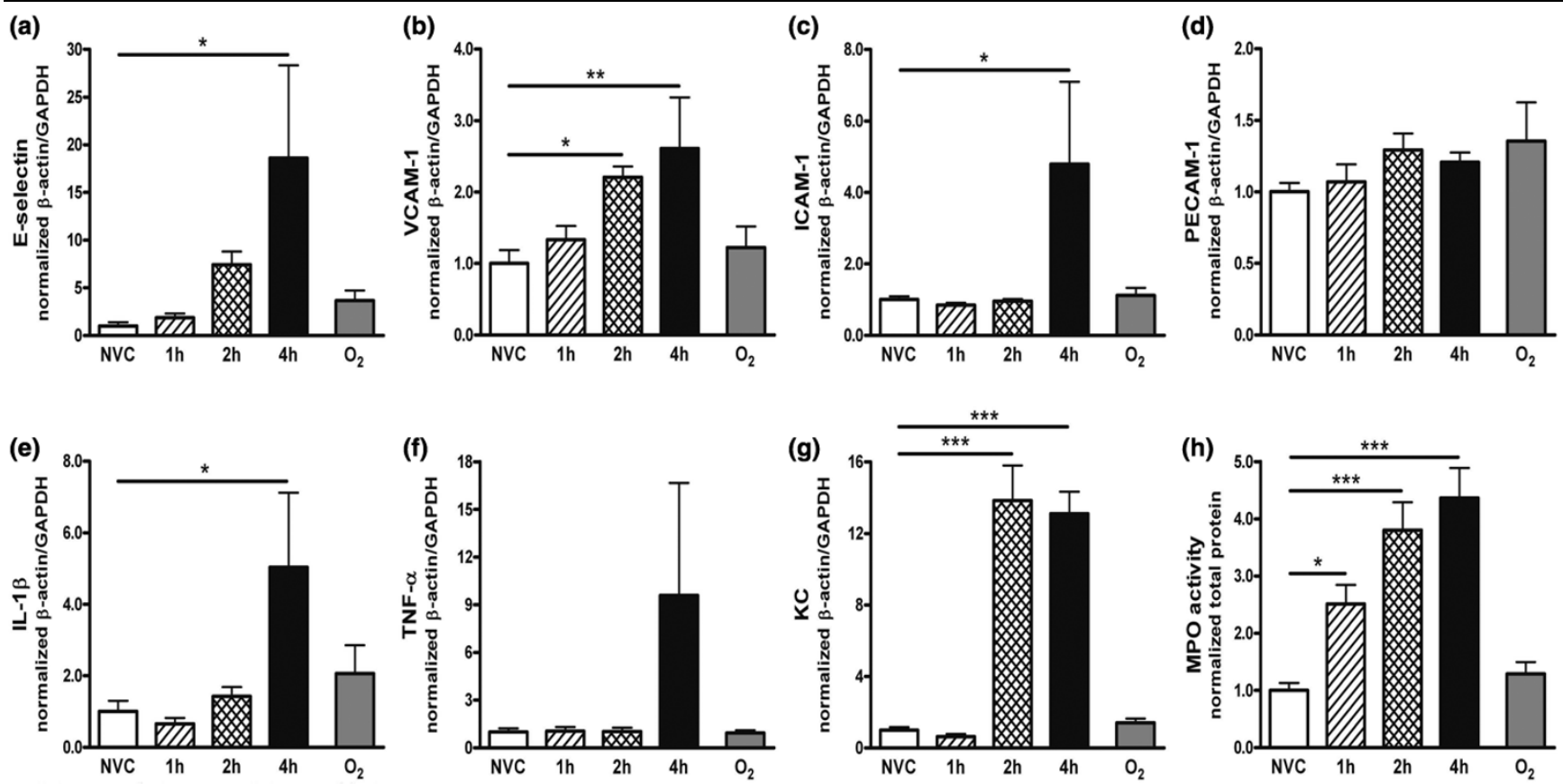

Ventilator-induced endothelial activation and inflammation in hepatic tissue. In total liver homogenates, mRNA expression of the adhesion molecules (a) E-selectin, (b) vascular cell adhesion molecule (VCAM)-1, (c) intercellular adhesion molecule (ICAM)-1 and (d) platelet-endothelial cell adhesion molecule (PECAM)-1 was determined by quantitative real time RT-PCR. In addition, we studied ventilator-induced hepatic inflammation by measuring mRNA expression of the pro-inflammatory cytokines (e) IL-1 $\beta$ and (f) TNF- $\alpha$ and the chemokine (g) keratinocyte-derived chemokine (KC). In total liver homogenates, $(\mathrm{h})$ myeloperoxidase (MPO) activity was determined as a measure of granulocyte infiltration. Data are expressed as mean \pm standard error of the mean of four to eight mice for each group $\left({ }^{*} P<0.05,{ }^{\star \star} P<0.01,{ }^{\star \star \star} P<0.001\right.$ vs. non-ventilated controls (NVC)). $1 \mathrm{~h}=$ mechanically ventilated for one hour; $2 \mathrm{~h}=$ mechanically ventilated for two hours; $4 \mathrm{~h}=$ mechanically ventilated for four hours; $\mathrm{O}_{2}=$ hyperoxia for four hours; GAPDH = glyceraldehyde 3-phosphate dehydrogenase.

\section{Contribution of hyperoxia}

We examined whether the high oxygen levels associated with our MV strategy might contribute to changes in the response of distal organs by exposing spontaneously breathing mice to $100 \%$ oxygen levels for four hours. Figures 3 and 4 illustrate that de novo synthesis of adhesion molecules, cytokines and chemokines, and MPO activity were comparable in hepatic and renal tissue of hyperoxia-exposed mice and NVC.

\section{Discussion}

To investigate the effects of alveolar stretch on endothelial activation and inflammation in the lung and organs distal to the lung, healthy mice were exposed to a MV strategy that has been described to cause overstretch of pulmonary tissue $[24,25]$. During four hours of MV, blood gas values remained within the physiological range and pulmonary architecture was preserved suggesting that the cardio-pulmonary integrity was maintained throughout the experiment. Our major finding was that MV induced de novo synthesis of various adhesion molecules represented by an elevation of E-selectin and VCAM-1 mRNA in pulmonary tissue and a rise in E-selectin, VCAM-1 and ICAM-1 mRNA in hepatic and renal tissues but not in cerebral tissue. Moreover, we noticed a time-dependent increase in cytokine and chemokine mRNA expression after MV which was accompanied by elevated recruitment of granulocytes. Importantly, this enhanced pro-inflammatory state was found both in the lung and distal organs.

There is convincing evidence that leukocyte-endothelial interactions play a crucial role in the pathogenesis of serious inflammatory diseases related to VILI, such as ALI and ARDS $[28,29]$. Gando and colleagues observed that soluble levels of P-selectin, E-selectin, ICAM-1 and VCAM-1 were enhanced within 24 hours after the diagnosis of ALI or ARDS [13]. Furthermore, these authors showed a marked increase in these soluble adhesion molecules when subdividing patients into survivors and non-survivors implying that adhesion molecules may have prognostic value for the development and clinical outcome of ALI or ARDS. The present study demonstrates that alveolar stretch imposed by MV induces activation of pulmonary endothelium in healthy mice, as measured by higher mRNA expression of E-selectin and VCAM-1. Our results are supported by in vitro models of cyclic strain and shear stress showing increased endothelial expression of adhesion molecules from the selectin family and Ig superfamily [30,31]. Therefore, it appears that ventilator-induced endothelial activation facilitates migration and adhesiveness of activated immune cells to inflamed pulmonary tissue, which in turn may 

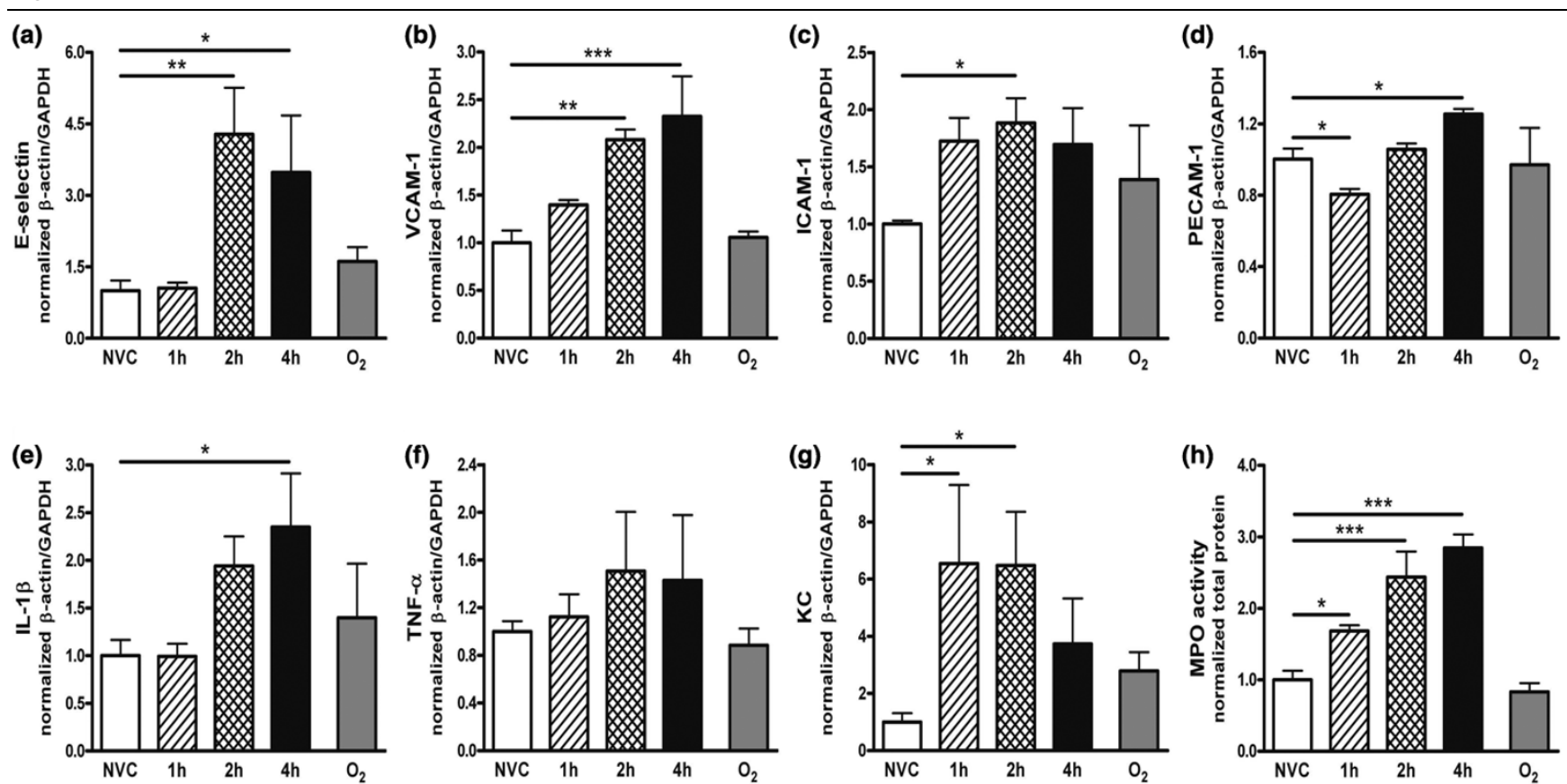

Ventilator-induced endothelial activation and inflammation in renal tissue. In total kidney homogenates, mRNA expression of the adhesion molecules (a) E-selectin, (b) vascular cell adhesion molecule (VCAM)-1, (c) intercellular adhesion molecule (ICAM)-1 and (d) platelet-endothelial cell adhesion molecule (PECAM)-1 was determined by quantitative real time RT-PCR. In addition, we studied ventilator-induced renal inflammation by measuring mRNA expression of the pro-inflammatory cytokines (e) IL-1 $\beta$ and (f) TNF- $\alpha$ and the chemokine (g) keratinocyte-derived chemokine (KC). In total kidney homogenates, $(\mathrm{h})$ myeloperoxidase (MPO) activity was determined as a measure of granulocyte infiltration. Data are expressed as mean \pm standard error of the mean of four to eight mice for each group $\left({ }^{\star} P<0.05,{ }^{\star \star} P<0.01,{ }^{\star \star \star} P<0.001\right.$ vs. non-ventilated controls (NVC)). $1 \mathrm{~h}=$ mechanically ventilated for one hour; $2 \mathrm{~h}=$ mechanically ventilated for two hours; $4 \mathrm{~h}=$ mechanically ventilated for four hours; $\mathrm{O}_{2}=\mathrm{hyperoxia}$ for four hours; GAPDH = glyceraldehyde 3-phosphate dehydrogenase.

lead to tissue injury. Although MV enhanced the number of granulocytes and expression of pro-inflammatory cytokines or chemokines in the lung, significant changes in pulmonary architecture and oxygenation variables were not observed. In line with this, recent studies demonstrated that MV strategies that do not cause deterioration of pulmonary function per se are capable of provoking ventilator-induced lung inflammation $[25,32]$.

To our knowledge, only one other study investigated the effect of MV on expression of cell-bound adhesion molecules. Miyao and colleagues described that ventilation with high tidal volumes enhances P-selectin, VCAM-1 and ICAM-1 expression in pulmonary vasculature of healthy rats [14]. We observed that MV did not only cause up-regulation of adhesion molecules in the lung but also evoked de novo synthesis of E-selectin, VCAM-1 and ICAM-1 in organs distal to the lung, such as liver and kidney. Whether a dose response relation exists between the extent of alveolar stretch and effects on distal organs remains to be determined. It has been proposed previously that an elevation of adhesion molecule expression might contribute to tissue injury and ultimately to MOF by facilitating leukocyte activation and migration [22,23]. In line with this notion, we demonstrated that MV augments KC mRNA expression and MPO activity in hepatic and renal tissue. Our data indicate that alveolar stretch due to $\mathrm{MV}$ promotes endothelial activation, inflammatory mediator production and the presence of granulocytes in distal organs. Therefore, we propose that MV may play a significant role in the pathogenesis of MOF. Combined with other events, such as an endotoxin challenge, ventilator-induced effects on the lung and distal organs will be exacerbated $[33,34]$ and possibly underlie the high incidence of MOF in critically ill patients ventilated with high pressures and tidal volumes [35].

Studies describing the combined effects of high $\mathrm{PaO}_{2}$ levels and MV have revealed that hyperoxia may exacerbate VILI $[36,37]$. Li and colleagues have shown augmented lung injury in mice exposed to MV with high tidal volumes and hyperoxia compared with animals ventilated with room air [36]. Therefore, we investigated whether the high $\mathrm{PaO}_{2}$ levels associated with our MV strategy were contributing to the observed changes in expression of adhesion molecules, cytokines and chemokines, and recruitment of granulocytes. In our study, hyperoxia as such did not lead to pulmonary endothelial activation and inflammation. Furthermore, we noticed that the high $\mathrm{PaO}_{2}$ levels did not induce an augmented immune response in organs distal to the lung. Although we cannot exclude that 
hyperoxia is aggravating the stretch-induced inflammatory response in pulmonary tissue, we consider that effects of high $\mathrm{PaO}_{2}$ levels on the inflammatory state of the liver and kidney will not be the primary cause of distal organ activation. As the reference group in our study (NVC) could not be sedated for the same period as ventilated animals, we cannot exclude that anesthesia affects endothelial activation and inflammation by itself. However, we have previously shown that MV with injurious settings (PIP 32/PEEP 6) increased pulmonary macrophage inflammatory protein-2 expression and reduced splenocyte natural killer cell activity whereas MV with protective settings (PIP 14/PEEP 6) did not have these effects on inflammation [24]. Since the same type of anesthesia was applied in the two abovementioned groups, we propose that anesthesia as such does not induce the inflammatory response.

Taken together, we demonstrated that MV induces endothelial activation and inflammation in the lung but also in the liver and kidney. It remains to be determined which factors lead to the onset of this inflammatory response in distal organs. Haitsma and colleagues and Tutor and colleagues have shown that ventilator-induced permeability of the alveolar-capillary barrier causes release of inflammatory mediators into the systemic circulation [38,39]. In the present study, alveolar stretch imposed by MV enhanced mRNA expression of adhesion molecules and cytokines or chemokines in hepatic and renal tissue, thus inducing de novo synthesis of these mediators in organs distal to the lung. Furthermore, we observed granulocyte recruitment to the liver and kidney, and KC mRNA expression in the kidney already after one hour of MV. These results indicate that ventilator-induced changes of the immune response may occur simultaneously in the lung, liver and kidney, and imply that release of inflammatory mediators into the circulation is probably not the only cause of augmented endothelial activation or inflammation in distal organs. We cannot exclude, however, that cytokines in the systemic circulation induce de novo synthesis of adhesion molecules and cytokines or chemokines in distal organs.

It has been hypothesized that the physical stress of MV activates the sympathetic nervous system [19]. In this regard, Elenkov and colleagues and Straub and colleagues have proposed that stimulation of sympathetic nerve terminals evokes an inflammatory response in peripheral organs $[40,41]$. Catecholamines activate transcription factors such as nuclear factor kappa B in macrophages thereby promoting IL-1, TNF and IL-8 production, which in turn might result in an acute phase response in the liver, possibly via $\alpha$-adrenergic activation $[40,42,43]$. Therefore, the systemic endothelial activation and inflammation caused by ventilator-induced alveolar stretch may be explained by activation of sympathetic nerve terminals in organs distal to the lung. If so, blockade of adrenergic receptor function will give further insight into the mechanism of distal organ inflammation. Future studies should also aim to develop intervention strategies to prevent simultaneous endothelial activation or inflammation in the lung and distal organs during MV. Such intervention strategies may not only improve the efficacy of MV but could also contribute to preventing MOF.

\section{Conclusions}

We have shown that alveolar stretch imposed by four hours of MV did not only provoke de novo synthesis of adhesion molecules and recruitment of granulocytes in the lung but also in organs distal to the lung such as liver and kidney, although not the brain. Our results demonstrate that ventilator-induced endothelial activation and inflammation in both the lung and distal organs may be crucial factors in the pathogenesis of MOF.

\section{Key messages}

- Alveolar stretch imposed by MV induces de novo synthesis of adhesion molecules, cytokines and chemokines in the lung.

- Alveolar stretch imposed by MV induces de novo synthesis of adhesion molecules, cytokines and chemokines in organs distal to the lung, such as liver and kidney.

- Ventilator-induced endothelial activation and inflammation in both the lung and distal organs may be crucial factors in the pathogenesis of MOF.

\section{Competing interests}

The authors declare that they have no competing interests.

\section{Authors' contributions}

$\mathrm{MAH}$ performed the experimental work, interpreted the results and drafted the manuscript. MPH and PS performed the experimental work and were responsible for critical review of the manuscript. BL participated in study design and was responsible for critical review of the manuscript. $\mathrm{CH}, \mathrm{NJ}, \mathrm{AV}$ and $\mathrm{PC}$ supervised the study, were involved in interpreting the results and correcting the manuscript. All authors have read and have approved the final version of the manuscript.

\section{Acknowledgements}

The authors thank Henk Moorlag for expert technical assistance. They also thank Professor Dr Grietje Molema of the Laboratory of Endothelial Biomedicine and Vascular Drug Targeting Research (UMC Groningen, the Netherlands) for her useful advice. This study was financially supported by the Catharijne Foundation, the Netherlands.

\section{References}

1. Parker JC, Hernandez LA, Peevy KJ: Mechanisms of ventilatorinduced lung injury. Crit Care Med 1993, 21:131-143.

2. Dreyfuss D, Soler P, Basset G, Saumon G: High inflation pressure pulmonary edema. Respective effects of high airway pressure, high tidal volume, and positive end-expiratory pressure. Am Rev Respir Dis 1988, 137:1159-1164. 
3. Mead J, Takishima T, Leith D: Stress distribution in lungs: a model of pulmonary elasticity. J Appl Physiol 1970, 28:596-608.

4. Ricard JD, Dreyfuss D, Saumon G: Ventilator-induced lung injury. Eur Respir J Supp/ 2003, 42:2s-9s.

5. Tremblay LN, Slutsky AS: Ventilator-induced injury: from barotrauma to biotrauma. Proc Assoc Am Physicians 1998, 110:482-488.

6. Tremblay LN, Slutsky AS: Ventilator-induced lung injury: from the bench to the bedside. Intensive Care Med 2006, 32:24-33.

7. Pugin J, Dunn I, Jolliet P, Tassaux D, Magnenat JL, Nicod LP, Chevrolet JC: Activation of human macrophages by mechanical ventilation in vitro. Am J Physiol 1998, 275:L1040-L1050.

8. Meager A: Cytokine regulation of cellular adhesion molecule expression in inflammation. Cytokine Growth Factor Rev 1999, 10:27-39.

9. Luscinskas FW, Gimbrone MA Jr: Endothelial-dependent mechanisms in chronic inflammatory leukocyte recruitment. Annu Rev Med 1996, 47:413-421.

10. Shanley TP, Warner RL, Ward PA: The role of cytokines and adhesion molecules in the development of inflammatory injury. Mol Med Today 1995, 1:40-45.

11. Carlos TM, Harlan JM: Leukocyte-endothelial adhesion molecules. Blood 1994, 84:2068-2101.

12. Calfee CS, Eisner MD, Parsons PE, Thompson BT, Conner ER Jr, Matthay MA, Ware LB: Soluble intercellular adhesion molecule1 and clinical outcomes in patients with acute lung injury. Intensive Care Med 2009, 35:248-257.

13. Gando S, Kameue T, Matsuda N, Sawamura A, Hayakawa M, Kato $\mathrm{H}$ : Systemic inflammation and disseminated intravascular coagulation in early stage of ALI and ARDS: role of neutrophil and endothelial activation. Inflammation 2004, 28:237-244.

14. Miyao N, Suzuki Y, Takeshita K, Kudo H, Ishii M, Hiraoka R, Nishio K, Tamatani T, Sakamoto S, Suematsu M, Tsumura H, Ishizaka A, Yamaguchi K: Various adhesion molecules impair microvascular leukocyte kinetics in ventilator-induced lung injury. $A m \mathrm{~J}$ Physiol Lung Cell Mol Physiol 2006, 290:L1059-L1068.

15. Ferring $M$, Vincent JL: Is outcome from ARDS related to the severity of respiratory failure? Eur Respir J 1997, 10:1297-1300.

16. Montgomery AB, Stager MA, Carrico CJ, Hudson LD: Causes of mortality in patients with the adult respiratory distress syndrome. Am Rev Respir Dis 1985, 132:485-489.

17. Ranieri VM, Giunta F, Suter PM, Slutsky AS: Mechanical ventilation as a mediator of multisystem organ failure in acute respiratory distress syndrome. JAMA 2000, 284:43-44.

18. Slutsky AS, Tremblay LN: Multiple system organ failure. Is mechanical ventilation a contributing factor? Am J Respir Crit Care Med 1998, 157:1721-1725.

19. Plotz FB, Slutsky AS, van Vught AJ, Heijnen CJ: Ventilatorinduced lung injury and multiple system organ failure: a critical review of facts and hypotheses. Intensive Care Med 2004, 30:1865-1872.

20. Bone RC: Toward a theory regarding the pathogenesis of the systemic inflammatory response syndrome: what we do and do not know about cytokine regulation. Crit Care Med 1996, 24:163-172.

21. Borrelli E, Roux-Lombard P, Grau GE, Girardin E, Ricou B, Dayer $J$, Suter PM: Plasma concentrations of cytokines, their soluble receptors, and antioxidant vitamins can predict the development of multiple organ failure in patients at risk. Crit Care Med 1996, 24:392-397.

22. Bone RC: The pathogenesis of sepsis. Ann Intern Med 1991, 115:457-469.

23. Parrillo JE: Pathogenetic mechanisms of septic shock. $N$ Engl $J$ Med 1993, 328:1471-1477.

24. Vreugdenhil HA, Heijnen CJ, Plotz FB, Zijlstra J, Jansen NJ, Haitsma JJ, Lachmann B, van Vught AJ: Mechanical ventilation of healthy rats suppresses peripheral immune function. Eur Respir J 2004, 23:122-128.

25. Wolthuis EK, Vlaar AP, Choi G, Roelofs JJ, Juffermans NP, Schultz $\mathrm{MJ}$ : Mechanical ventilation using non-injurious ventilation settings causes lung injury in the absence of pre-existing lung injury in healthy mice. Crit Care 2009, 13:R1.

26. Bergmann KC, Lachmann $B$, Noack K: Lung mechanics in orally immunized mice after aerolized exposure to influenza virus. Respiration 1984, 46:218-221.
27. Nijboer $\mathrm{CH}$, Kavelaars $\mathrm{A}$, Vroon $\mathrm{A}$, Groenendaal $\mathrm{F}$, van $\mathrm{BF}$, Heijnen CJ: Low endogenous G-protein-coupled receptor kinase 2 sensitizes the immature brain to hypoxia-ischemia-induced gray and white matter damage. J Neurosci 2008, 28:3324-3332.

28. Abraham E: Neutrophils and acute lung injury. Crit Care Med 2003, 31:S195-S199.

29. Moraes TJ, Chow CW, Downey GP: Proteases and lung injury. Crit Care Med 2003, 31:S189-S194.

30. Sampath R, Kukielka GL, Smith CW, Eskin SG, Mclntire LV: Shear stress-mediated changes in the expression of leukocyte adhesion receptors on human umbilical vein endothelial cells in vitro. Ann Biomed Eng 1995, 23:247-256.

31. Yun JK, Anderson JM, Ziats NP: Cyclic-strain-induced endothelial cell expression of adhesion molecules and their roles in monocyte-endothelial interaction. J Biomed Mater Res 1999, 44:87-97.

32. Cobelens PM, van Putte BP, Kavelaars A, Heijnen CJ, Kesecioglu $\mathrm{J}$ : Inflammatory consequences of lung ischemia-reperfusion injury and low-pressure ventilation. J Surg Res 2009, 153:295-301.

33. Imai Y, Parodo J, Kajikawa O, de PM, Fischer S, Edwards V, Cutz E, Liu M, Keshavjee S, Martin TR, Marshall JC, Ranieri VM, Slutsky AS: Injurious mechanical ventilation and end-organ epithelial cell apoptosis and organ dysfunction in an experimental model of acute respiratory distress syndrome. JAMA 2003, 289:2104-2112.

34. O'Mahony DS, Liles WC, Altemeier WA, Dhanireddy S, Frevert CW, Liggitt D, Martin TR, Matute-Bello G: Mechanical ventilation interacts with endotoxemia to induce extrapulmonary organ dysfunction. Crit Care 2006, 10:R136.

35. Schultz MJ: Lung-protective mechanical ventilation with lower tidal volumes in patients not suffering from acute lung injury: a review of clinical studies. Med Sci Monit 2008, 14:RA22-RA26

36. Li LF, Liao SK, Ko YS, Lee CH, Quinn DA: Hyperoxia increases ventilator-induced lung injury via mitogen-activated protein kinases: a prospective, controlled animal experiment. Crit Care 2007, 11:R25.

37. Sinclair SE, Altemeier WA, Matute-Bello G, Chi EY: Augmented lung injury due to interaction between hyperoxia and mechanical ventilation. Crit Care Med 2004, 32:2496-2501.

38. Haitsma JJ, Uhlig S, Goggel R, Verbrugge SJ, Lachmann U, Lachmann B: Ventilator-induced lung injury leads to loss of alveolar and systemic compartmentalization of tumor necrosis factoralpha. Intensive Care Med 2000, 26:1515-1522.

39. Tutor JD, Mason CM, Dobard E, Beckerman RC, Summer WR, Nelson S: Loss of compartmentalization of alveolar tumor necrosis factor after lung injury. Am J Respir Crit Care Med 1994, 149:1107-1111.

40. Elenkov IJ, Wilder RL, Chrousos GP, Vizi ES: The sympathetic nerve--an integrative interface between two supersystems: the brain and the immune system. Pharmacol Rev 2000, 52:595-638.

41. Straub RH, Mayer M, Kreutz M, Leeb S, Scholmerich J, Falk W: Neurotransmitters of the sympathetic nerve terminal are powerful chemoattractants for monocytes. J Leukoc Biol 2000, 67:553-558

42. Flierl MA, Rittirsch D, Nadeau BA, Sarma JV, Day DE, Lentsch AB Huber-Lang MS, Ward PA: Upregulation of phagocyte-derived catecholamines augments the acute inflammatory response. PLOS ONE 2009, 4:e4414.

43. Spengler RN, Allen RM, Remick DG, Strieter RM, Kunkel SL: Stimulation of alpha-adrenergic receptor augments the production of macrophage-derived tumor necrosis factor. $J$ Immunol 1990, 145:1430-1434. 